\title{
Identification of NURR1 as a Mediator of MIF Signaling During Chronic Arthritis
}

\section{Effects on Glucocorticoid-Induced MKP1}

Jennifer A. Ralph, * Afsar U. Ahmed, ${ }^{*}$ Leilani L. Santos, ${ }^{\star}$ Andrew R. Clark, ${ }^{\dagger}$ Jason McMorrow, ${ }^{\ddagger}$ Evelyn P. Murphy, ${ }^{\ddagger}$ and Eric F. Morand*

From the Centre for Inflammatory Diseases, ${ }^{*}$ the Department of Medicine, Monash University, Monash Medical Centre, Melbourne, Australia; the Kennedy Institute of Rheumatology Division, ${ }^{\dagger}$ Imperial College London, London, United Kingdom; and the College of Life Sciences, ${ }^{\ddagger}$ University College Dublin Veterinary Sciences Centre, Conway Institute of Biomolecular and Biomedical Research, University College Dublin, Dublin, Ireland

Elucidation of factors regulating glucocorticoid (GC) sensitivity is required for the development of "steroid-sparing" therapies for chronic inflammatory diseases, including rheumatoid arthritis (RA). Accumulating evidence suggests that macrophage migration inhibitory factor (MIF) counterregulates the GC-induction of anti-inflammatory mediators, including mitogen-activated protein kinase phosphatase 1 (MKP1), a critical mitogen-activated protein kinase signaling inhibitor. This observation has yet to be extended to human disease; the molecular mechanisms remain unknown. We investigated NURR1, a GC-responsive transcription factor overexpressed in RA, as a MIF signaling target. We reveal abrogation by recombinant MIF (rMIF) of GC-induced MKP1 expression in RA fibroblast-like synoviocytes (FLS). rMIF enhanced NURR1 expression, artificial NBRE (orphan receptor DNA-binding site) reporter transactivation, and reversed GC-inhibition of NURR1. NURR1 expression was reduced during experimental arthritis in MIF $^{-/-}$synovium, and silencing MIF reduced RA FLS NURR1 mRNA. Consistent with NBRE identification on the MKP1 gene, MKP1 mRNA was reduced in FLS that ectopically express NURR1, and silencing NURR1 enhanced MKP1 MRNA in RA FLS. rMIF enhanced NBRE binding on the MKP1 gene, and the absence of the NBRE prevented NURR1-repressive effects on basal and
GC-induced MKP1 transactivation. This study defines NURR1 as a novel MIF target in chronic inflammation and demonstrates a role for NURR1 in regulating the anti-inflammatory mediator, MKP1. We propose a MIF-NURR1 signaling axis as a regulator of the GC sensitivity of MKP1. (Am J Pathol 2010, 177:2366-2378; DOI: 10.2353/ajpath.2010.091204)

Chronic systemic inflammatory diseases such as rheumatoid arthritis (RA) are characterized by an imbalance between pro- and anti-inflammatory regulatory influences. During early RA, the synovial tissue (synovium) lining the joint capsule is transformed into an invasive and destructive tissue (pannus), which progressively compromises joint integrity. ${ }^{1}$ Activated fibroblast-like synoviocytes (FLS) and macrophages within the pannus produce pro-inflammatory cytokines, including interleukin (IL)- $1 \beta$, tumor necrosis factor $\alpha$ and macrophage migration inhibitory factor (MIF), matrix-degrading enzymes, and proangiogenic mediators. ${ }^{1-3}$ Activation of mitogen-activated protein kinases (MAPKs), namely p38 MAP kinase, c-Jun $\mathrm{N}$-terminal kinase, and extracellular signal-regulated kinase, plays a central role in integrating cellular responses to such pro-inflammatory signals in RA. ${ }^{4}$

Adrenal glucocorticoids (GCs) produced in response to circulating pro-inflammatory cytokines provide a significant counterregulatory influence on immune-inflammatory activation. ${ }^{5}$ GCs also induce MIF expression in RA synovial cells, ${ }^{3}$ which presents a paradox given the

Supported by an Endeavour Australia-Europe Fellowship (J.A.R.) and Australian National Health and Medical Research Council (NHMRC) grant number 519512 (J.A.R. and E.F.M.).

Accepted for publication July 1, 2010.

None of the authors disclosed any relevant financial relationships. Current address of J.A.R.: Science Foundation Ireland, Dublin, Ireland. Address reprint requests to Eric F. Morand, MBBS (Hons.) FRACP, Ph.D., Centre for Inflammatory Diseases, Monash University Department of Medicine, Monash Medical Centre, 246 Clayton Rd, Clayton, Melbourne 3168, Australia. E-mail: eric.morand@med.monash.edu.au. 
profile of MIF-regulated pro-inflammatory events in $\mathrm{RA}^{3,6-11}$ and the profound protection afforded by MIF deficiency in terms of reduced disease severity in multiple murine models of arthritis. ${ }^{7,12,13}$ However, it is now accepted that a key physiological role of MIF is its antagonism of the inhibitory effects of endogenous GCs on inflammation, ${ }^{14-16}$ with the effect that inflammation can be perpetuated despite the inhibitory effects of endogenous GCs. The negative regulator of MAPK activation, MAPK phosphatase 1 (MKP1), has been identified as a key MIF-regulated gene operative in these responses. ${ }^{15,16}$

MKP1 (CL100, PTPN10, DUSP1, and 3CH134) is 1 of 10 MAPK phosphatases (MKPs) characterized to date which tightly control the phosphorylation of MAPKs. ${ }^{17}$ MKPs provide an energy efficient mode of inactivation for phosphorylated MAPK proteins, through phosphatase activity at the phosphothreonine and phosphotyrosine residues of their activated targets. MKPs are hence also referred to as dual specificity protein phosphatases, and each has distinct subcellular localizations and substrate specificities. ${ }^{17}$ MKP1, the archetypal dual specificity protein phosphatase, is predominantly localized to the nucleus, and although it has the capacity to dephosphoylate all three MAPK families, MKP1 has a substrate preference for p38 and c-Jun N-terminal kinase. ${ }^{18}$ MKP1 is encoded by an immediate early gene and, as such, is rapidly induced by stimuli such as lipopolysaccharide, UV-radiation, serum, GCs, and cytokines. ${ }^{19-23} \mathrm{An}$ accumulating literature supports a role for MKP1 as a modulator of immune responses ${ }^{17,24-30}$ and suggests that GC-induced MKP1 expression constitutes a major antiinflammatory action of GCs on MAPK signaling, including repression of the prostaglandin producing enzyme COX2. ${ }^{22,30-33}$ MKP1 is of pivotal importance in determining disease severity and lethality in models of endotoxic shock, diabetes, anaphylaxis, and RA. ${ }^{24-27,29}$ Salojin et $\mathrm{al}^{26}$ demonstrated that MKP1-deficient mice have increased systemic levels of pro-inflammatory cytokines and autoantibodies, and markedly exacerbated disease development in the collagen-induced arthritis model of RA, compared with their wild-type (WT) equivalents. This suggests a central position for MKP1 in the hierarchy of mediators in RA. We previously described the expression and regulation of MKP1 in RA FLS 22 ; however, little is known about mechanisms of MKP1 regulation in these cells.

We and others have described a role for MIF as a suppressor of GC-induced MKP1 expression in murine macrophages, ${ }^{15,16}$ suggesting that MKP1 is a molecular target of MIF-GC cross talk during inflammation. However, this observation has not been extended to human cells and the molecular mechanisms remain unknown. In particular, identification of an inflammatory mediator responsive to both MIF and GCs is lacking. The nuclear orphan receptor NURR1 (NR4A2) is a strong candidate in this regard.

Members of the orphan receptor subfamily (NR4A) of nuclear receptors, NURR1, NUR77 (NR4A1), and NOR-1 (NR4A3), play an important coordinate neuroendocrine regulatory role throughout the hypothalamic-pituitary-ad- renal axis. ${ }^{34}$ NURR1 knockout mice die soon after birth due to a lack of dopaminergic neurons ${ }^{35}$ and consequently, accumulating evidence supports NURR1 as a potential therapeutic target for Parkinson's disease. ${ }^{36,37}$ NR4A subfamily members are increasingly emerging as key regulators of cytokine and growth factor action in the periphery. ${ }^{38-45}$ As immediate early genes and ligandindependent constitutively active transcription factors, activity is tightly controlled at the level of expression. Both pro- and anti-inflammatory roles have been ascribed to NR4A subfamily members, ${ }^{36,38-42,44,46}$ and their overexpression has been reported in inflamed arthritic synovial tissue, atherosclerotic lesions, and cancer cells compared with normal tissue. ${ }^{40,42,46}$ We have previously demonstrated that NURR1 is the major cytokine-regulated member of the NR4A subfamily in inflamed human synovium and cartilage. ${ }^{38,39,41,44,46}$ NURR1 characteristically regulates target gene expression through interaction with a specific consensus sequence in the promoters of target genes, known as the nerve growth factor-induced clone B response element (NBRE). ${ }^{47}$ Phosphorylation or interaction with other transcription factors and co-regulatory proteins can also influence NURR1-mediated gene regulation. ${ }^{38,48-50}$ The repertoire of NURR1regulated genes, including matrix metalloproteinases (MMPs), IL-8, corticotropin-releasing hormone, osteocalcin, and osteopontin, further supports the hypothesis that NURR1 is a key regulator of joint biology. ${ }^{38,39,41,51,52}$ In turn, key inflammatory mediators produced within the inflamed joint, including prostaglandin $E_{2}$, tumor necrosis factor $\alpha, \mathrm{IL}-1 \beta$, parathyroid hormone (PTH), and corticotropin-releasing hormone, regulate NURR1 expression. $38,39,44,46,53$ Importantly, NURR1 expression in RA FLS is inhibited by immunomodulatory drugs, including methotrexate and the GC, dexamethasone (DEX). ${ }^{39,44}$

The profile of effects of NURR1 in inflammation and its position as a convergence point of distinct pro- and anti-inflammatory pathways suggest NURR1 as a potential effector of the antagonistic effects of MIF and GCs on MKP1. Using primary synoviocytes and in vivo studies, we define NURR1 as a novel molecular target of MIF in chronic inflammation, and underscore a role for NURR1 in MKP1 regulation. We demonstrate herein, that NURR1 is a novel regulator of MKP1 expression and represents a mediator through which MIF and GCs counterregulate this critical protein.

\section{Materials and Methods}

\section{RA FLS Isolation and Cell Culture}

FLS were obtained from the synovium of patients with RA, and isolated and cultured as previously described. ${ }^{7}$ NIH3T3, a murine fibroblast cell line (American Type Culture Collection, Manassas, VA), were cultured in $10-\mathrm{cm}$ culture plates in a $5 \% \mathrm{CO}_{2}$ humidified incubator at $37^{\circ} \mathrm{C}$ in Dulbecco's modified Eagle's medium (Sigma, Melbourne, Australia) supplemented with 10\% fetal calf serum (Sigma) and penicillin streptomycin $(100 \mathrm{U} / \mathrm{ml}$; Sigma). Cells were placed in serum-free media 24 hours 
before stimulation. Recombinant MIF (rMIF; provided by Cortical Pty Ltd, Melbourne, Australia) and dexamethasone (Sigma) were included in the cell cultures at indicated concentrations.

\section{Generation of Cell Lines Ectopically Expressing NURR1}

K4 IM cells (provided by Professor H. Eibel, University Hospital, Freiburg, Germany), an immortalized human synoviocyte cell line, were cultured as described for FLS. K4 IM cells were stably transfected with a pUB6/NURR1 expression vector or a pUB6 control vector by Cell Trends, Inc. (Middletown, MD) using a nonliposomal liquid technique. Forty-eight hours post-transfection the medium was replaced with medium supplemented with 10 $\mu \mathrm{g} / \mathrm{ml}$ blasticidin. The selective medium was then replaced every 3 to 4 days until blasticidin-resistant colonies were detected. Single colonies overexpressing NURR1 or the pUB6 control vector were then selected and propagated in selection medium.

\section{Western Blotting}

Cells were lysed in lysis buffer (Cell Signaling, Beverly, MA) supplemented with phosphatase (Sigma) and protease (Roche, NSW, Australia) inhibitor cocktails according to the manufacturer's instructions. Equal amounts of cellular proteins were boiled for 5 minutes in SDS loading buffer and fractionated on $4 \%$ to $20 \%$ SDS-polyacrylamide Precise protein gradient gels (Pierce, Rockford, IL). The resolved proteins were transferred onto nitrocellulose sheets that were immunoblotted overnight at $4^{\circ} \mathrm{C}$ with a monoclonal $\beta$ Actin antibody (1:10,000; Sigma) or a polyclonal NURR1 antibody (N20; 1:1000; Santa Cruz Biotechnology, Santa Cruz, CA). Secondary antibodies, goat anti-rabbit Alexa Fluor 680, and goat anti-mouse Alexa Fluor 750 (1:10,000; Invitrogen Molecular Probes, Melbourne, Australia) were used for protein detection as required. Immunoblots were visualized by using the Odyssey infra-red imaging system (Li-Cor Biosciences, Lincoln, NE).

\section{Reverse-Transcription and Quantitative RT-PCR Analysis}

Total RNA was extracted and reverse-transcribed into cDNA as previously described. ${ }^{44}$ Quantitative PCR was conducted by using SYBR Green JumpStart Taq ReadyMix (Sigma) and the Corbett Rotor-gene 3000 (Corbett Life Science, NSW, Australia). Primers for NURR1, ${ }^{51}$ MKP $1,{ }^{54} \mathrm{COX} 2,{ }^{9}$ and $\beta \mathrm{Actin}^{22}$ were described previously. The primers used for MIF amplification were sense 5'-TCATCGTAAACACCAACGTGC-3'; antisense 5'-GCCGCGTTCATGTCGTAATA-3' and for IL-8 amplification were sense 5'-TTGGCAGCCTTCCTGATTTC-3'; antisense 5'-AACTTCTCCACAACCCTCTGCA-3'.

Reactions were analyzed in $10 \mu$ l volumes by using 0.3 $\mu \mathrm{mol} / \mathrm{L}$ primers and an optimized CDNA dilution in sterile water for each primer pair: NURR1 (1:30), MIF (1:10), MKP1 (1:100), COX2, IL-8, and BActin (1:20). Forty-five cycles of PCR were programmed. Expression levels of each mRNA and their estimated crossing points in each sample were determined relative to a standard preparation by using the Corbett Rotor-gene computer software (Corbett Life Science). Melting curve analysis of amplification products was performed at the end of each PCR reaction, and a ratio of specific $\mathrm{mRNA} / \beta$ Actin amplification was then calculated. PCR products were confirmed by agarose gel electrophoresis. Where indicated, MKP1 results are normalized to glyceraldehyde-3-phosphate dehydrogenase by using the $2^{-} \Delta \Delta \mathrm{Ct}$ method of relative quantitation.

\section{Animals and Antigen-Induced Arthritis}

MIF deficient $\left(\mathrm{MIF}^{-1-}\right)$ mice were generated as previously described. ${ }^{7} \mathrm{MIF}^{-1-}$ and WT littermates (B6/129) were bred and housed under specific pathogen-free conditions in the animal facility of Monash Medical Centre until used for experiments, during which they were maintained in conventional housing. All animal experiments were performed in accordance with Monash University Animal Ethics Committee regulations. Antigen-induced arthritis was induced and assessed in mice (10 to 14 weeks of age) as previously described. ${ }^{7,10}$ Resulting histological sections were scored 0 to 3 for four parameters $^{10}$ : synovitis, joint space exudates, cartilage degradation, and bone damage. An average was taken of the four scored parameters for each animal and this represented the final histological score.

\section{Immunofluorescence and Confocal Microscopy}

FLS were cultured in Lab-tek 8-chamber slides or 24-well plates (Nunc, Rochester, NY) for immunofluorescence. Following treatment, media was removed and cells were washed in cold PBS. Cells were air-dried and fixed in $1 \%$ paraformaldehyde for 10 minutes before incubation in $15 \%$ goat serum from the rabbit Vectastain ABC kit (Vector Laboratories, Burlingame, CA) for 1 hour. NURR1 primary antibody (N20; $1: 50)$ or MKP1 primary antibody (1:100; Upstate Biotechnology, Lake Placid, NY) was incubated on cells for 1 hour. Cells were incubated in the same concentration of normal rabbit IgG as a control (Becton Dickinson, Franklin Lakes, NJ). This was followed by addition of anti-rabbit IgG-Alexa 568 (1:400; Invitrogen Molecular Probes) or donkey anti-rabbit IgG-fluorescein isothiocyanate (1:20; Santa Cruz Biotechnology) secondary antibodies for 1 hour. The chamber slides were mounted in Vectastain fluorescent mounting media (Vector Laboratories) and analyzed by using a fluorescent or confocal microscope (Leica, Wetzlar, Germany).

\section{NURR1 Immunohisto/Cytochemistry}

Immunohistochemistry was conducted by using the rabbit Vectastain ABC kit and the N20 NURR1 primary antibody (1:100) and scored as previously described. ${ }^{44}$ For 
immunocytochemistry, cells were cultured in Lab-tek 8-chamber slides (Nunc) and identical immunostaining procedures used as those for histological sections.

\section{Construction of MKP1-Luc Reporters}

MKP1-Luc-NBRE was constructed by cloning a 3.0-kb human MKP1 5' fragment $(-2726 /+211)$ into the M/u1 site upstream of the luciferase coding region in a pGL3 reporter system (pGL3b; Promega, Hampshire, UK). MKP1-Luc+NBRE was constructed by cloning the NBRE-containing intron $3(0.4 \mathrm{~kb})$ from human MKP1 gene into the BamH1 and Sall sites downstream of the luciferase coding region of MKP1-Luc-NBRE. Constructs were verified by sequencing and restriction enzyme digest analyses.

\section{Transient Transfection and Reporter Assays}

RA FLS $\left(0.75 \times 10^{6}\right)$ at $80 \%$ confluence were transfected by using nucleofector technology (Amaxa, Cologne, Germany) using the Human Dermal Fibroblast Nucleofector kit (NHDF; Amaxa) and program U23. FLS were nucleofected with $1 \mu \mathrm{g}$ of $\mathrm{NBRE}_{3}$-tk-luc in combination with $1 \mu \mathrm{g}$ of pCMX-NURR1 (both kindly provided by Professor Thomas Perlmann, Ludwig Institute for Cancer Research, Sweden) or pCMV control plasmid. Each nucleofection sample was divided over three wells of a 24-well plate permitting triplicate readings of a single nucleofection.

NIH3T3 were transfected by using lipofectamine (Invitrogen Molecular Probes). Cells were seeded (150,000/ well) in 24-well plates according to the manufacturer's instructions, and transfected 18 hours later with $0.25 \mu \mathrm{g}$ $\mathrm{NBRE}_{3}$-tk-luc in combination with $0.25 \mu \mathrm{g}$ pCMX-NURR1 or pCMV control plasmid. For the MKP1-luc assays, NIH3T3 (25,000/well) were transfected with $0.83 \mu \mathrm{g}$ of MKP1-luc-+NBRE or MKP1-luc-NBRE, in combination with equal amounts of pCMX-NURR1 or PCMV control plasmid. Each transfection was performed in triplicate.

Transfection efficiencies of a control Green Fluorescent Protein (GFP) plasmid in RA FLS and NIH3T3 were greater than $70 \%$. After 18 hours, the media was changed and cells were either left nontreated or treated with rMIF or DEX. Media was removed from each well and the cells were washed with cold PBS. Cells were lysed in $100 \mu$ l reporter lysis buffer according to the manufacturer's instructions (Promega). Twenty microliters of lysate was mixed with 100 $\mu$ l luciferase reagent (Promega) and assayed for luciferase activity by using a luminometer (Wallac, Perkin Elmer, Turku, Finland).

\section{Small-Interfering RNA Knockdown}

MIF expression in FLS was knocked down by using MIF-specific oligonucleotides (sense: 5'-CCUUCUGGUGGGGAGAAAUtt-3'; antisense: 5'-AUUUCUCCCCACCAGAAGGtt-3'; Ambion, Austin, TX). NURR1-specific oligonucleotides were commercially available (Dharmacon, Chicago, IL; catalog number D-003427-04) and previously described. ${ }^{55}$ FLS $\left(0.75 \times 10^{6}\right)$ were nucleofected with $1 \mu \mathrm{mol} / \mathrm{L}$ oligonucleotides directed against MIF or
Table 1. Total Histological and NURR1 Scoring of Wild-Type and $\mathrm{MIF}^{-1-}$ Synovia

\begin{tabular}{cccl}
\hline Score & Wild-type & $\mathrm{MIF}^{-1-}$ & \multicolumn{1}{c}{$P$} \\
\hline Total histological $^{*}$ & $5.8 \pm 1.1$ & $2.3 \pm 0.7$ & 0.02 \\
NURR1 & $3.8 \pm 0.3$ & $1.8 \pm 0.1$ & 0.003 \\
\hline
\end{tabular}

Note: Values are the mean \pm SEM; wild-type, $n=5$; MIF-deficient $\left(\mathrm{MIF}^{-1-}\right), n=7$.

*Total histological score is a composite score of synovitis, joint space exudates, and degradation of cartilage and bone. $P$ values were determined by using the Student's $t$-test.

NURR1 or a nontargeting small-interfering RNA (siRNA) control, and RNA or protein was extracted at the indicated time point. siRNA experiments were performed multiple times for each patient sample and similar results obtained.

\section{Electromobility Shift Assay}

The LightShift Chemiluminescent Electromobility Shift Assay (EMSA) kit (Pierce) was used to detect proteins bound to a region of the MKP1 gene spanning 2078-2096 bp. Nuclear extracts were prepared as described previously. ${ }^{46}$ Complimentary MKP1 oligonucleotides were synthesized with $3^{\prime}$ biotin labels (5'-TGTGTGTACTGGAAAGAGT-3', 5'ACTCTTTCCAGTACACACA-3'; Invitrogen). Biotinylated annealed probe $(20 \mathrm{fmol})$ was incubated with 5 to $10 \mu \mathrm{g}$ nuclear extract, $1 \times$ binding buffer, $2.5 \%$ glycerol, $5 \mathrm{mmol} / \mathrm{L}$ $\mathrm{MgCl}_{2}, 50 \mathrm{ng} / \mu \mathrm{l}$ Poly (dl-dC), and $0.05 \% \mathrm{NP}-40$ for 20 minutes at room temperature. Where indicated, N2O and E20 TransCruz antibodies (Santa Cruz Biotechnology), normal rabbit IgG, or $200 \times$ unlabeled competitor DNA was included in binding reactions. Equal amounts of proteinDNA complexes were resolved on $6 \%$ DNA retardation gels (Invitrogen) and transferred onto Biodyne nylon membrane (Pierce). Biotinylated DNA was detected by using the streptavidin-horseradish peroxidase conjugate and chemiluminescent substrate, followed by exposure to X-ray film.

\section{Statistics}

The Student's t-test was used for analysis of gene expression studies and transfection data. Pearson correlation coefficient was used to test for correlation between histological scores (Table 1).

\section{Results}

\section{rMIF Opposes the Effects of GCs on MKP1 Expression in RA FLS}

The effects of MIF on GC-induced MKP1 expression in RA were determined in primary RA FLS. MKP1 mRNA was measured by quantitative RT-PCR in RA FLS after treatment with DEX for 1 hour in the presence and absence of rMIF. Consistent with previous observations, ${ }^{22}$ DEX significantly $(P<0.005)$ induced MKP1 mRNA expression in RA FLS (Figure 1A). This induction was significantly $(P<0.05)$ inhibited by $\mathrm{rMIF}$ in these cells 
A

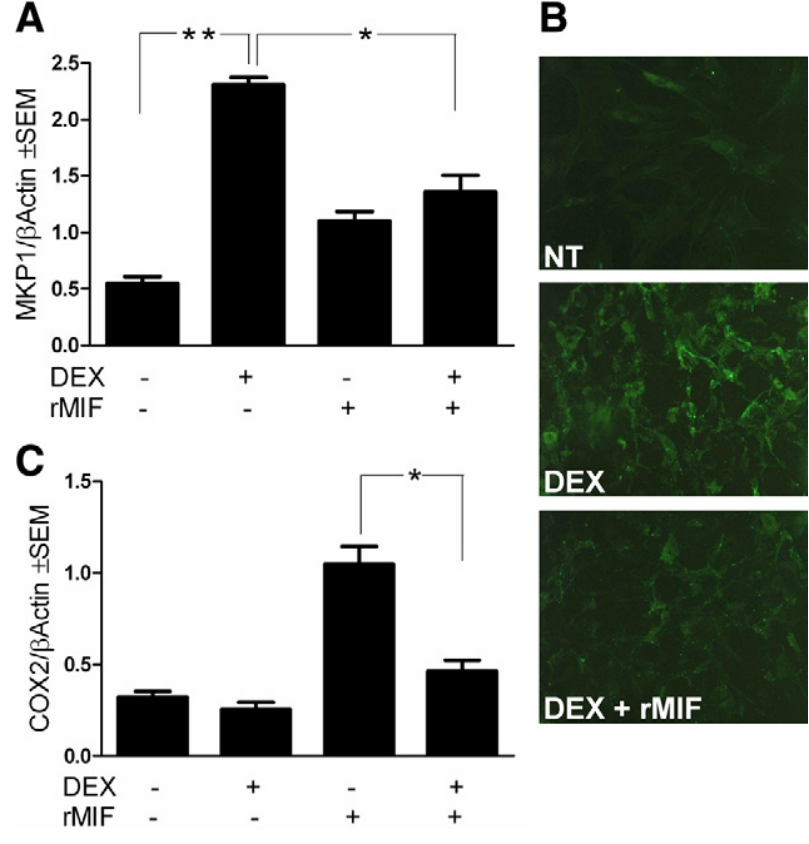

Figure 1. rMIF opposes the effects of GCs on MKP1 expression in RA FLS. Total RNA was isolated from RA FLS $(n=4)$ left nontreated or treated with dexamethasone $10^{-8} \mathrm{M}(\mathrm{DEX}) \pm \operatorname{rMIF}(100 \mathrm{ng} / \mathrm{ml})$ for one hour. Quantitative RT-PCR was performed for (A) MKP1, (C) COX2, and $\beta$ Actin. Values are MKP1 or COX2 mRNA levels \pm SEM normalized to $\beta$ Actin. ${ }^{*} P<0.05 ;{ }^{* * *} P<$ 0.005 . B: Representative immunofluorescence analysis of RA FLS $(n=3)$ that were nontreated (NT) or treated with $\operatorname{DEX}\left(10^{-8} \mathrm{M}\right)$ alone or in combination with rMIF $(100 \mathrm{ng} / \mathrm{ml})$ for six hours, before incubations with rabbit antiMKP1 antibody and donkey anti-rabbit IgG-fluorescein isothiocyanate. Original magnification, $\times 400$

(Figure 1A). Antagonism by MIF of GC-induced MKP1 in RA FLS was confirmed at the protein level by immunofluorescence, which demonstrated a decrease in both cytoplasmic and nuclear immunostaining (Figure 1B).

To confirm an inflammatory repercussion of MIF modulation of GC-induced MKP1, we examined regulation of COX2 mRNA by rMIF and DEX in RA FLS by quantitative RT-PCR. $\mathrm{MIF}$ is a key regulator of the expression of the prostaglandin synthesis enzyme COX2, a major phenotype of RA FLS. 9,11 COX2-derived prostaglandins perpetuate signaling of proinflammatory mediators in RA, including the nuclear orphan receptor NURR1, ${ }^{46,56}$ and COX2 regulation by GCs has been reported to require MKP1. ${ }^{20}$ As expected, DEX did not affect basal COX2 expression (Figure 1C). DEX significantly $(P<0.05)$ reversed rMIF induction of COX2 mRNA expression in RA FLS (Figure 1C).

\section{rMIF Enhances NURR1 Expression and NBRE Transactivation}

Inhibition by MIF of GC-regulated MKP1 in RA FLS prompted investigation of a candidate mediator of MIF and GC effects on MKP1 in RA. To determine the contribution of NURR1 in this regard, we first investigated the effects of rMIF on NURR1 expression in RA FLS. Quantitative RT-PCR analysis demonstrated a robust and significant $(P<0.05)$ increase in NURR1 mRNA expression by rMIF in RA FLS (Figure 2A). Western blotting demonstrated NURR1 protein induction in response to $\mathrm{rMIF}$ stimulation from 1 to 3 hours (Figure 2B). The effects of rMIF on NURR1 protein localization were explored in RA FLS by confocal microscopy (Figure 2C). NURR1 protein was primarily localized to the cytoplasm in nontreated FLS, as indicated by diffuse red immunofluorescence. Upon rMIF stimulation, RA FLS acquired a stellate morphology, accompanied by increased NURR1 immunofluorescence with predominant nuclear localization. The effect of rMIF on NURR1 induction and localization was equivalent to that of prostaglandin $\mathrm{E}_{2}$, a major contributor to synovial NURR1 expression. ${ }^{44,46}$ The specificity of NURR1 immunofluorescence was verified by incubation with isotype-matched nonimmune IgG (data not shown).

Having demonstrated a role for MIF as a novel regulator of NURR1 expression, we sought to investigate the capacity of MIF to modulate NBRE transactivation. A fibroblast cell line (NIH3T3 cells) was transfected with an artificial NBREdriven luciferase reporter (NBRE-tk-luc) with and without a NURR1 overexpression plasmid (pCMX-NURR1), stimulated with $\mathrm{rMIF}$, and assessed for luciferase activity. rMIF significantly $(P<0.005)$ enhanced transactivation of the NBRE reporter in these cells (Figure 2D). Consistent with previous studies describing this reporter, ${ }^{38}$ NBRE transactivation was increased over eightfold when co-transfected with pCMX-NURR1 (Figure 2D). rMIF significantly $(P<$ 0.005 ) augmented pCMX-NURR1-mediated transactivation of the NBRE site (Figure 2D). Further experiments confirmed significantly $(P<0.05)$ increased NBRE transactivation by rMIF in RA FLS (Figure 2E).

\section{MIF Deficiency Reduces NURR1 Expression in Experimental Arthritis and RA}

In vivo studies have established that endogenous MIF is associated with inflammatory activation in RA and experimental arthritis, ${ }^{7,12,13}$ and increased NURR1 expression in synovium from patients with inflammatory arthritides, including RA, has been previously described. ${ }^{39,44}$ To further elucidate the contribution of MIF to dysregulated NURR1 expression in RA, we investigated the effects of the absence of endogenous MIF on NURR1 expression in arthritic mice and human RA FLS.

Consistent with previous reports, ${ }^{7,10}$ arthritis severity was markedly decreased in $\mathrm{MIF}^{-1-}$ animals compared with WT (Figure 3A). $\mathrm{MIF}^{-1-}$ mice displayed reduced synovitis, cartilage degradation (Figure $3 A$ ), and joint space exudate, which gave rise to a significant difference between total histological scores of WT $(5.8 \pm 1.1)$ and $\mathrm{MIF}^{-/-}$mice (2.3 $\pm 0.7 ; P=0.02$; Table 1$)$. The pattern of NURR1 immunostaining was markedly different between the synovium of WT and $\mathrm{MIF}^{-1-}$ animals (Figure 3B). NURR1 was widely distributed throughout inflamed WT synovium with predominant nuclear localization. This pattern of immunostaining is consistent with that observed following rMIF stimulation of RA FLS (Figure 2C). In contrast, $\mathrm{MIF}^{-1-}$ synovium displayed significantly lower NURR1 positivity $(P=0.003$; Table 1$)$. NURR1 immunostaining in $\mathrm{MIF}^{-1-}$ synovium was mostly restricted to the cytoplasm (Figure 3B). The reduction in arthritis severity 
A

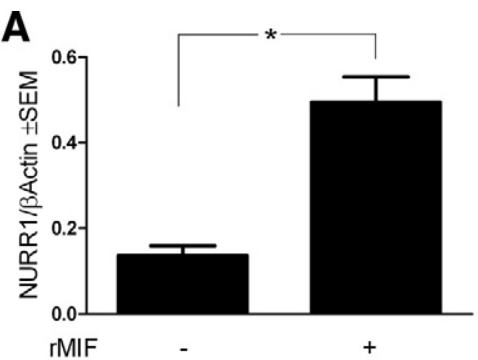

B
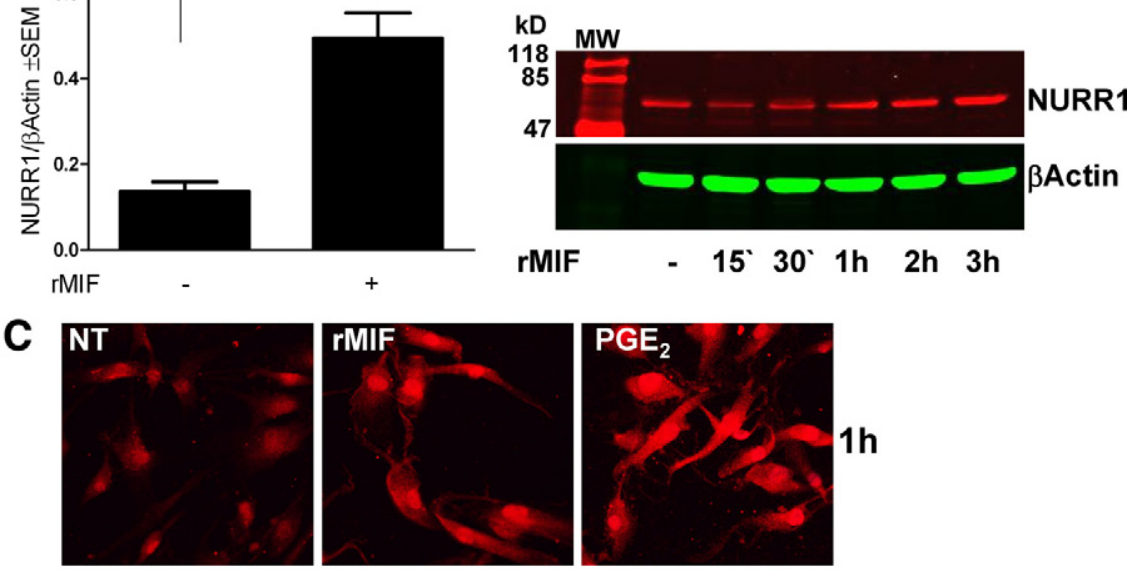

$1 \mathrm{~h}$
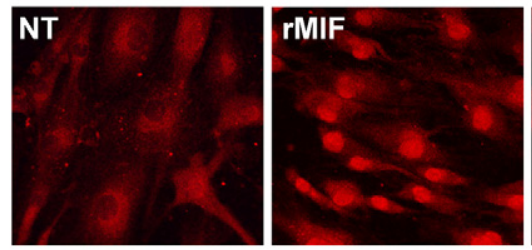

D

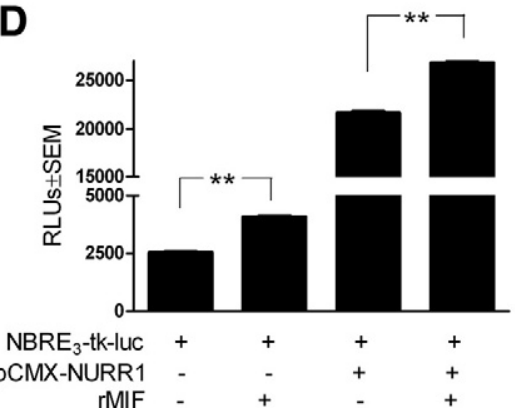

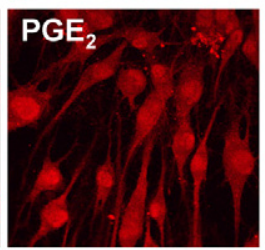

E

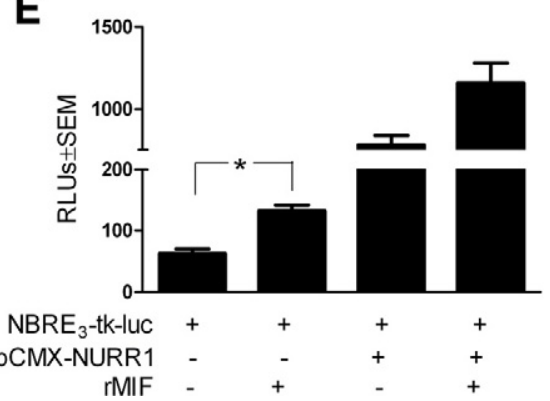

Figure 2. rMIF enhances NURR1 expression and NBRE transactivation. A: Total RNA was isolated from RA FLS $(n=8)$ left nontreated or treated with rMIF $(100 \mathrm{ng} / \mathrm{ml})$ for 1 hour. Quantitative RT-PCR was performed by using primers for NURR1 and $\beta$ Actin. Values are NURR1 mRNA levels \pm SEM normalized to $\beta$ Actin. ${ }^{*} P<0.05$. B: Representative Western blot analysis of protein extracts from RA FLS that were nontreated or treated with rMIF $(100 \mathrm{ng} / \mathrm{ml})$ for up to three hours. Immunoblots were probed with rabbit anti-NURR1 and mouse anti- $\beta$ Actin antibodies. MW, molecular weight marker. C: Representative confocal microscopy analysis of RA FLS $(n=3)$ that were nontreated (NT) or treated with rMIF $(100 \mathrm{ng} / \mathrm{ml})$ or prostaglandin $\mathrm{E}_{2}$ $\left(\mathrm{PGE}_{2} ; 10^{-6} \mathrm{M}\right)$ for 1 or 3 hours, before incubations with rabbit anti-NURR1 antibody and goat anti-rabbit Alexa Fluor 568. Original magnification, $\times 700$. D: NIH3T3 cells were transfected with $0.25 \mu \mathrm{g} \mathrm{NBRE}$-tk-luc reporter in combination with $0.25 \mu \mathrm{g}$ control plasmid or pCMXNURR1. After 24 hours, cells were nontreated or treated with $\mathrm{rMIF}(100 \mathrm{ng} / \mathrm{ml})$ for a further 24 hours. Luciferase activity was determined in cell lysates. Values (RLUs, relative luciferase units \pm SEM) are triplicate luciferase readings representative of three transfections. E: RA FLS were nucleofected with $1 \mu \mathrm{g} \mathrm{NBRE}_{3}$-tk-luc reporter in combination with $1 \mu \mathrm{g}$ control plasmid or pCMX-NURR1. After 24 hours, cells were nontreated or treated with $\mathrm{rMIF}(100 \mathrm{ng} / \mathrm{ml})$ for further 24 hours. Luciferase activity was determined in cell lysates. Values (RLUs \pm SEM) are triplicate luciferase readings of one representative nucleofection. ${ }^{*} P<0.05$; ${ }^{* * *} P<0.005$. correlated significantly $(r=0.727 ; P=0.007)$ with reductions in NURR1 expression.

We next sought to examine the effects of endogenous MIF on NURR1 expression in RA FLS. MIF siRNA treatment of RA FLS resulted in almost total abrogation of MIF mRNA levels (Figure $3 \mathrm{C}$ ) and this was further confirmed by inhibition of the MIF and NURR1 target gene, IL-8 (Figure 3C). NURR1 mRNA expression was significantly $(P<0.05)$ inhibited in RA FLS, underscoring MIF as a significant contributor to NURR1 expression in RA FLS (Figure 3C).

\section{rMIF Reverses Inhibition of NURR1 Expression by GCs in RA FLS}

Given reports demonstrating inhibitory effects of GCs on NURR1 in RA, ${ }^{39}$ we sought to determine whether the effects of DEX and rMIF on NURR1 expression in RA FLS were opposing. DEX significantly $(P<0.05)$ inhibited NURR1 mRNA expression in RA FLS, and rMIF significantly $(P<$ $0.05)$ negated this inhibition, as determined by quantitative RT-PCR (Figure 4A). The opposing effects of rMIF and DEX on NURR1 were verified at the protein level by immunocytochemistry (Figure 4B). Consistent with our earlier experi- ments (Figure 2, B and C), rMIF-stimulated RA FLS exhibited increased NURR1 protein expression compared with nontreated cells, an effect inhibited by DEX (Figure 4B).

\section{MKP1 Is Modulated by NURR1 Expression}

Collectively, the data thus far suggested a role for MIF in opposing the effects of GCs on each of MKP1 and NURR1. We next investigated the contribution of NURR1 expression to that of MKP1 by using a human FLS cell line genetically altered to stably and ectopically express NURR1. Three NURR1 ectopically expressing cell lines (numbers 1 to 3 ) expressed NURR1 protein levels two- to fourfold greater than basal levels in WT cells (Figure 5A). MKP1 mRNA, as determined by quantitative RT-PCR analysis, was markedly and significantly $(P<0.005)$ reduced in cells ectopically expressing NURR1, compared with control cells (Figure 5B). This observation suggests a repressive role for NURR1 on MKP1 expression in FLS.

We next investigated whether NURR1 expression impinges on inducible MKP1 mRNA levels in RA FLS. Using an siRNA approach with a previously validated oligonucleotide, ${ }^{55}$ NURR1 expression was silenced in RA FLS (Figure 5C). NURR1 knockdown resulted in significantly 

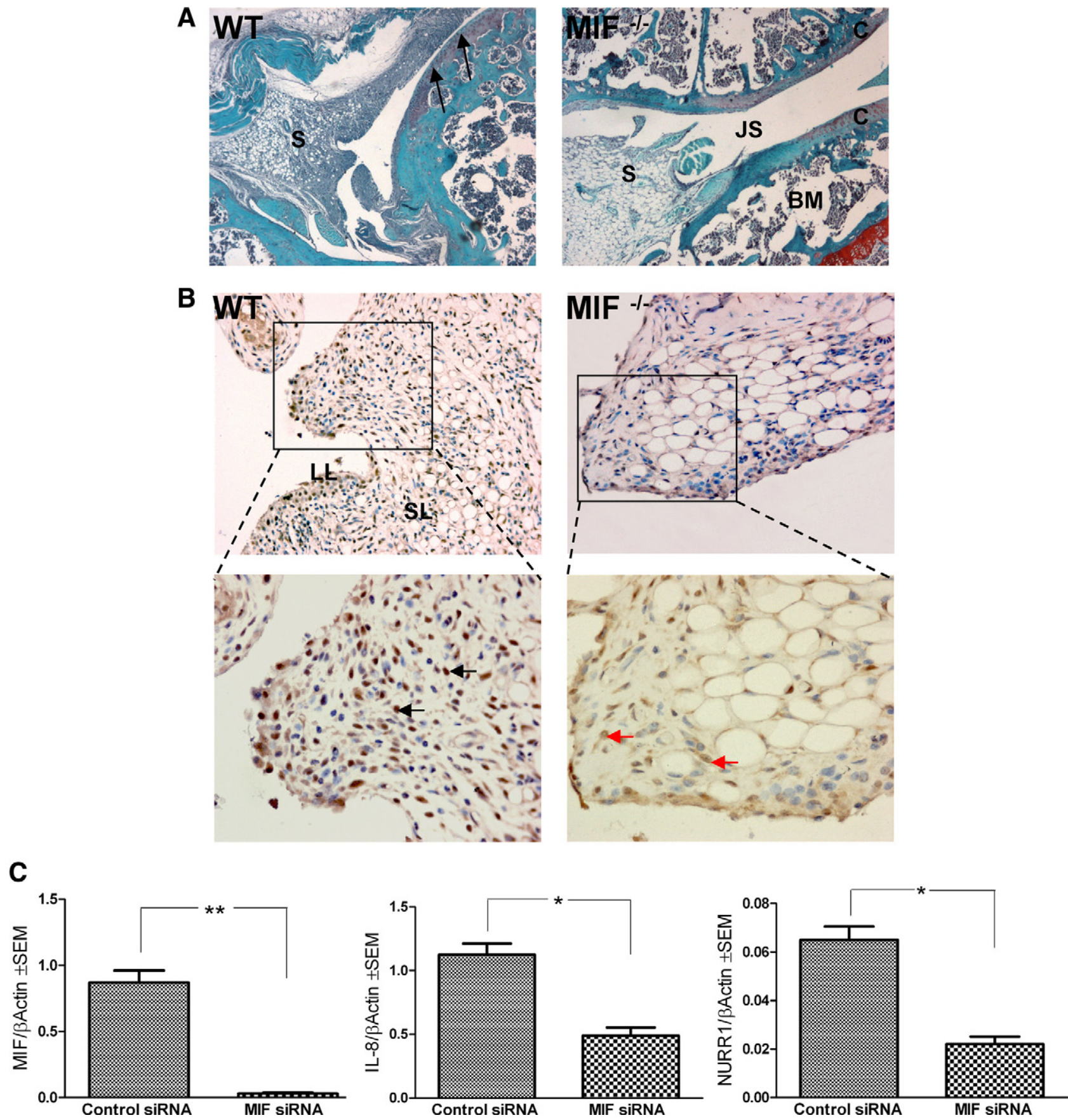

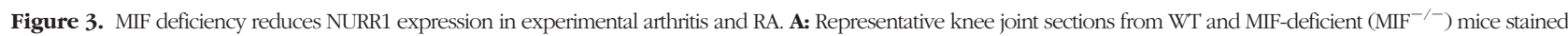
with safranin O to distinguish cartilage regions (pink/red) and counterstained with fast green (green). Nuclei were counterstained with hematoxylin (blue/purple). S, Synovium; JS, joint space; BM, bone marrow; $\mathrm{C}$, cartilage; double arrows, cartilage degradation. Original magnification, $\times 50$. B: Representative synovial tissue sections from WT and MIF antigen-induced arthritis mice immunostained with rabbit anti-NURR1 antibody. Positive immunoreactivity appears brown/black for NURR1. Nuclei were counterstained with hematoxylin (blue/purple). Black and red arrows indicate examples of nuclear and cytoplasmic immunostaining, respectively. LL, lining layer; SL, sublining layer. Areas denoted by open squares in the top panels (original magnification, $\times 200$ ) are presented at increased magnification in the bottom panels (original magnification, X400). C: RA FLS $(n=$ 4) were nucleofected with $1 \mu \mathrm{mol} / \mathrm{L}$ siRNA directed against MIF or a nontargeting siRNA control. After 24 hours, total RNA was isolated and quantitative RT-PCR was performed by using primers for MIF, IL-8, NURR1, and $\beta$ Actin. Values are MIF, IL-8, or NURR1 mRNA levels \pm SEM normalized to $\beta$ Actin. ${ }^{*} P<0.05 ;{ }^{* * *} P<0.005$.

$(P<0.05)$ enhanced MKP1 mRNA levels in RA FLS in the presence of rMIF and DEX (Figure 5D). Notwithstanding the antagonistic signaling mechanisms between MIF and GCs during chronic inflammation, this observation suggests the repressive effect of NURR1 on MKP1 expression persists in an environment in which both pro- and anti-inflammatory stimuli are operational.

\section{An NBRE Is Located on the MKP1 Gene and Functions as a Repressive Site}

The effects of NURR1 on MKP1 expression suggested the presence of an NBRE on the MKP1 gene. Using MatInspector software, we identified a putative NBRE at position 2078-2096 bp in the third intron on the reverse 
A

B
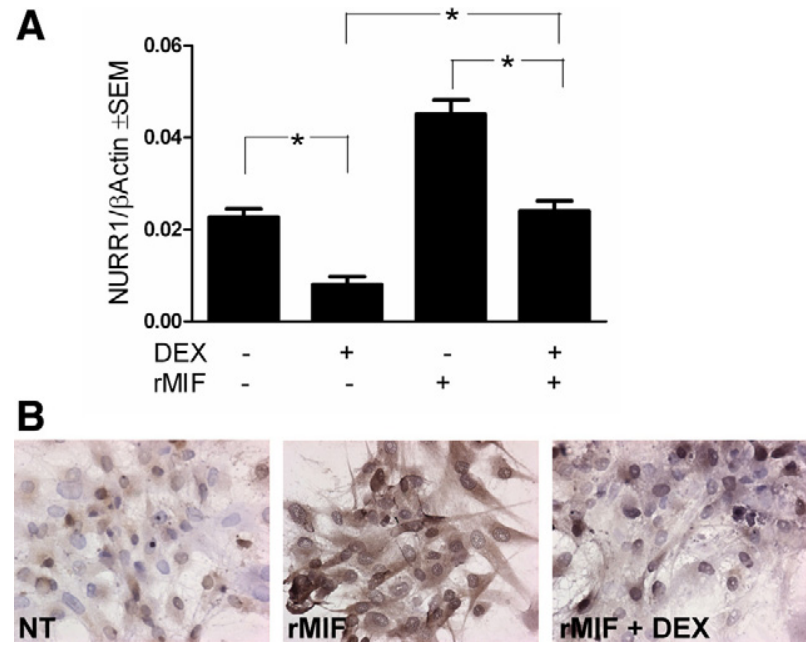

Figure 4. rMIF reverses inhibition of NURR1 expression by GCs in RA FLS. A: Total RNA was isolated from RA FLS $(n=5)$ left nontreated or treated with dexamethasone $10^{-8} \mathrm{M}(\mathrm{DEX}) \pm \operatorname{rMIF}(100 \mathrm{ng} / \mathrm{ml})$ for one hour. Quantitative RT-PCR was performed for NURR1 and $\beta$ Actin. Values are NURR1 mRNA levels \pm SEM normalized to $\beta$ Actin. ${ }^{*} P<0.05$. B: Representative immunocytochemical analysis of RA FLS that were nontreated (NT) or treated with rMIF $(100 \mathrm{ng} / \mathrm{ml})$ alone or in combination with DEX $\left(10^{-8} \mathrm{M}\right)$, before incubation with rabbit anti-NURR1 antibody. Positive immunoreactivity appears brown/black. Original magnification, $\times 400$.

strand of the MKP1 gene (GenBank accession number: NM_004417; Figure 6A).

To determine whether MIF enhances binding directly to the NBRE on the MKP1 gene, we performed EMSA experiments focusing on the 19-bp region centered on the identified NBRE. Nuclear extracts from a fibroblast cell line, nontreated or treated with rMIF, bound to this region and a specific high-molecular mass complex were identified by competition with unlabeled oligonucleotide (Figure 6B, lane 4, specific complex arrow). We observed a marked increase in intensity of the specific complex in nuclear extracts from rMIF-treated cells (Figure 6B, lane 3) compared with nontreated cells (Figure 6B, lane 2), indicating that an $\mathrm{rMIF}$-induced factor increased binding to this NBRE region. To confirm the presence of NURR1 in this complex, we included E20 (directed against the C-terminal) and N2O (directed against the N-terminal) polyclonal anti-NURR1 antibodies in the binding reactions. Both antibodies decreased the intensity of the specific complex induced by rMIF in both cell types (Figure $6 \mathrm{~B}$, lanes 5 and 6 , respectively) indicating that DNAbinding by NURR1 was inhibited in the presence of these NURR1-specific antibodies. Control rabbit IgG did not alter the binding pattern of the specific complex (data not shown). This confirms that NURR1 is a component of an rMIF-induced complex that binds to the NBRE on the MKP1 gene.

To verify the repressive function of the NBRE in NURR1-mediated regulation of MKP1 expression, we constructed a luciferase reporter (MKP1-luc) driven by the $-2726 /+211$ fragment of the human MKP1 gene with (+NBRE) and without (-NBRE) the NBRE-containing intronic region. A fibroblast cell line was transfected with MKP1-luc+NBRE or MKP1-luc-NBRE, in the presence and absence of pCMX-NURR1, and stimulated with DEX. Consistent with our mRNA analysis (Figure 1A), DEX enhanced MKP1-luc transactivation of both reporters (Figure 6, C and D). Co-transfection with pCMX-NURR1 significantly $(P<0.005)$ repressed basal and DEX-induced transactivation of MKP1-luc in the presence of the NBRE (Figure 6C). Conversely, repression of MKP1-luc by PCMX-NURR1 was not observed in the absence of the NBRE (Figure 6D).

\section{Discussion}

Reports of the pivotal importance of MKP1 in the severity and lethality of experimental models of endotoxic shock, diabetes, and RA have demonstrated a nonredundant role for MKP1 in innate and adaptive immune responses. ${ }^{24,26,27,29}$ A major additional function of MKP1 is as an effector of anti-inflammatory GC action. ${ }^{22,30,32,33}$ We
A

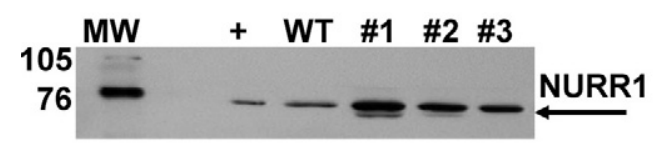

C

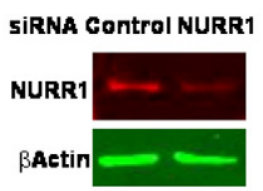

B
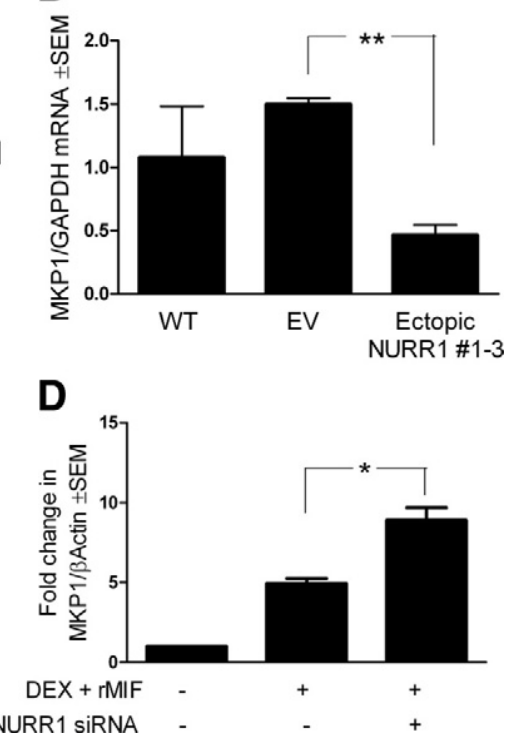

Figure 5. MKP1 is modulated by NURR1 expression. A: Western blot analysis of nuclear protein extracts from WT or K4 IM synoviocytes ectopically expressing NURR1 (cell lines numbers 1 to 3 ) Immunoblots were probed with rabbit anti-NURR1 antibody; +, positive control; MW, molecular weight marker $(\mathrm{kDa})$. B: Total RNA was isolated from K4 IM synoviocytes that were nontreated (WT), transfected with empty vector (EV), or that ectopically expressed NURR1 (cell lines numbers 1 to 3). MKP1 and glyceraldehyde-3-phosphate dehydrogenase (GAPDH) mRNA levels were determined by quantitative RT-PCR. Values are MKP1 mRNA levels \pm SEM normalized to GAPDH. ${ }^{* * *} P<$ 0.005 . C and D: RA FLS were nucleofected with 1 $\mu \mathrm{mol} / \mathrm{L}$ siRNA directed against NURR1 or a nontargeting siRNA control. Twenty-four hours later, total RNA and protein were extracted from RA FLS left nontreated or co-treated with rMIF $(100 \mathrm{ng} / \mathrm{ml})$ and dexamethasone $10^{-8} \mathrm{M}$ (DEX) for 1 hour. $\mathbf{C}$ Representative Western blot analysis of NURR1 protein knockdown in RA FLS. Immunoblots were probed with rabbit anti-NURR1 and mouse anti- $\beta$ Actin antibodies. D: Quantitative RT-PCR was performed by using primers for MKP1 and $\beta$ Actin. Values are fold-change in MKP1 mRNA levels relative to control siRNA nucleofected cells and normalized to $\beta$ Actin. ${ }^{*} P<0.05$. 
A

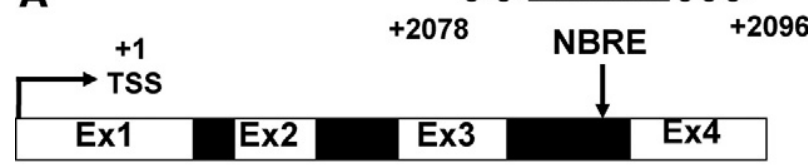

B
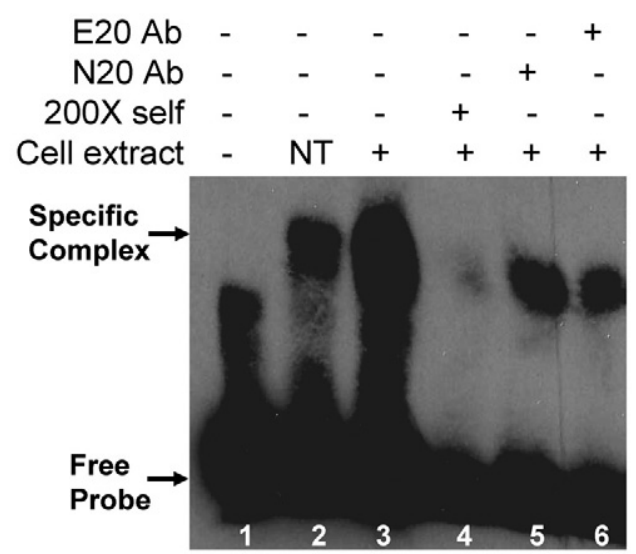

C

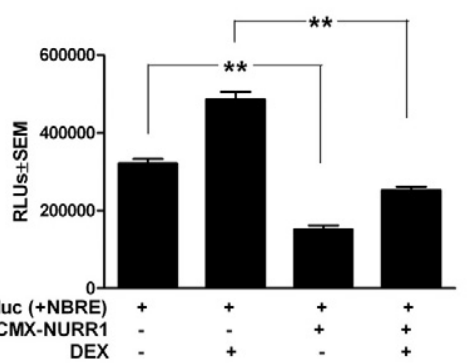

D

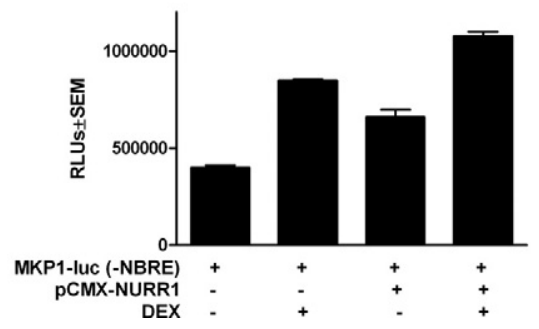

Figure 6. rMIF enhances binding to the $M K P 1$ gene NBRE, which functions as a transcriptional repressive site. A: Diagrammatic representation of the NBRE identified in the third intron on the MKP1 gene by using MatInspector; TSS, transcription start site. B: Representative EMSA of the NBRE region (2078-2096 bp) on the MKP1 gene. Nuclear extracts were prepared from a fibroblast cell line that was nontreated (lane 2) or treated with rMIF (100 $\mathrm{ng} / \mathrm{ml}$; lanes 3 to $\mathbf{6}$ ) for three hours. Equal concentrations of extract were incubated with a 19-bp biotinylated double-stranded oligonucleotide. Excess unlabeled oligonucleotide $(200 \times)$ was included in lane 4. N20 and E20 TransCruz antibodies were included in lanes $\mathbf{5}$ and $\mathbf{6}$ respectively. No extract was added to lane 1. C and D: Representative MKP1-luc reporter assays. A fibroblast cell line was transfected with $0.83 \mu \mathrm{g}($ C) MKP1-luc + NBRE or (D) MKP1-luc-NBRE, in combination with equal concentration of control plasmid or pCMX-NURR1. After 24 hours, cells were nontreated or treated with dexamethasone $10^{-7} \mathrm{M}$ (DEX) for a further 24 hours. Luciferase activity was determined in cell lysates. Values (RLUs, relative luciferase units \pm SEM) are triplicate luciferase readings representative of three transfections. ${ }^{* *} P<0.005$.

and others identified MKP1 as a molecular target of MIF-GC cross talk in murine macrophages, such that the presence of MIF limits the ability of GCs to induce MKP1 expression. ${ }^{15,16}$ In the current study, we present evidence to define the nuclear orphan receptor NURR1 as a target of MIF and GCs in RA, and as a repressor of MKP1 expression. Thus, we reveal a molecular mechanism un- derlying MIF regulation of GC sensitivity during chronic inflammation.

Studies using both in vitro and in vivo models have confirmed that MAPK signaling contributes significantly to key inflammatory events in RA, including cytokine and MMP production, and angiogenesis. ${ }^{57-60}$ Using the collagen-induced arthritis model of RA, Salojin et al ${ }^{26}$ provided the first in vivo evidence that MKP1, through its action as an endogenous MAPK inhibitor, is a critical inhibitory regulator of inflammation and the innate and adaptive immune responses in arthritis. Consistent with the role of MKP1 as an effector of GCs, the present results confirm induction of MKP1 expression by GCs in RA FLS. In keeping with previous reports of cytokine regulation of MKP1 in $R A,{ }^{22}$ we observe enhancement by rMIF of MKP1 mRNA levels, conceivably reflecting the capacity of MIF to activate MAPKs, ${ }^{9,13}$ which in turn have a role in MKP1 transcriptional regulation. ${ }^{21,23}$ Notwithstanding this action of MIF in isolation, as recently reviewed, the capacity of MIF to inhibit GC-induced MKP1 expression is thought to be a primary mechanism underpinning its physiological counterregulation of immunosuppressive GC effects. ${ }^{17}$ We report rMIF inhibition of GC-induced MKP1 expression in RA FLS, extrapolating for the first time MIF effects on MKP1 to human cells. Both in vitro and in vivo studies have shown that GC-induced MKP1 inhibits p38 and c-Jun N-terminal kinase activity, consequently suppressing a range of pro-inflammatory genes, including the prostaglandin-producing enzyme, COX2. ${ }^{20,22,32,33}$ We also identify parallel opposing effects of MIF and DEX on COX2 expression in RA FLS, underscoring an important inflammatory implication of opposing signaling between MIF and GCs in RA.

Members of the NR4A subfamily of orphan nuclear receptors are emerging as key regulators of cytokine and growth factor action in diseases characterized by prolonged or inappropriate inflammatory responses. ${ }^{39,40,43}$ Consistent with findings from Murphy et $\mathrm{al}^{38,39,41}$ demonstrating rapid transcriptional activation of NR4A genes by inflammatory mediators in joint tissues, reports also identify NR4A receptors as effector molecules of cytokine signaling in other cells including macrophages. ${ }^{42,43,45,61}$ Treatment of macrophages with lipopolysaccharide, cytokines, or oxidized lipids triggers the transcriptional induction of all three NR4A receptors. ${ }^{43,61}$ Functional studies from these and other reports demonstrate both pro- and anti-inflammatory functions for NR4A receptors, suggesting that acute or chronic expression levels of these receptors may permit differential effects on gene expression. ${ }^{36,38-41,45,61,62}$ Thus, target genes and physiological functions of NR4A receptors are likely to be tissue and context dependent. Modulation of NURR1 is a convergence point of pro- and anti-inflammatory pathways, and its activity is tightly controlled at the level of expression, post-translational modification, and subcellular localization. Therefore, control of NURR1 activity may facilitate a role for this transcription factor as a mediator of both proand anti-inflammatory signals.

Analyses of human RA synovium have described increased NURR1 expression in cells of the synovial lining layer, chondrocytes, and vascular endothelial cells, con- 
firming that NURR1 is expressed in cells implicated in invasive pannus. ${ }^{38,39,44,46}$ Our results demonstrate that rMIF is a robust inducer of NURR1 mRNA and protein expression in RA FLS, adding to the repertoire of MIF target genes in RA, which includes p53, IL-6, cytosolic phospholipase A2, and MMP2. ${ }^{7,9,11,13}$ Consistent with the induction of an activated FLS phenotype, rMIF promoted nuclear localization of NURR1 in RA FLS. This is further supported by the effects of rMIF on endogenous and NURR1-mediated transactivation of a luciferase reporter driven by three copies of the NBRE, indicating that MIF is a regulator of both NURR1 expression and activity in RA. The present study provides further evidence in support of MIF as a mediator of NURR1 expression in RA, via the first description of synovial NURR1 expression in experimental arthritis, and the demonstration that endogenous MIF supports NURR1 expression in inflamed synovium. Interestingly, the diffuse, cytoplasmic pattern of NURR1 synovial immunostaining observed in $\mathrm{MIF}^{-/-}$ mice is similar to that reported in human arthritic synovium obtained from patients undergoing successful treatment with methotrexate. ${ }^{44}$ Furthermore, we describe a significant reduction in NURR1 expression, with concomitant reductions in the expression of the pro-inflammatory chemoattractant and MIF target gene $I L-8,{ }^{63}$ in MIF siRNAtreated RA FLS. Interestingly, NURR1 has recently been confirmed as a transcriptional activator of $I L-8$ in RA. ${ }^{41}$

Having defined NURR1 as a target of MIF, we were interested to determine the effects of GCs on MIF-induced NURR1. DEX has previously been shown to inhibit cytokine-induced NURR1 transcription in RA FLS ${ }^{39}$ and our present results demonstrate inhibition by DEX of endogenous and rMIF-induced NURR1 mRNA and protein expression in these cells. Thus, similar to MKP1, GCs and MIF have opposing effects on NURR1 regulation, suggesting NURR1 as a candidate mediator of GC and MIF effects on MKP1 expression in RA. This role is supported by the reduction in MKP1 expression in an FLS cell line ectopically expressing NURR1. Moreover, within the complexity of an rMIF- and GC-stimulated environment, NURR1 siRNA treatment confirms that NURR1 inhibits MKP1 expression in RA FLS. Collectively, these data demonstrate a role for both MIF and NURR1 in inhibiting GC-regulated MKP1 in FLS, a finding with significant repercussions for MAPK-mediated events in RA, and potentially contributing to $\mathrm{GC}$ resistance in $\mathrm{RA}$ and other inflammatory diseases.

Transcriptional regulation of MKP1 has yet to be fully understood. Two functional CAMP response element binding protein sites have been identified on the MKP1 promoter $^{64}$ and more recent studies have verified a role for cAMP response element binding protein and activator protein-1 as transcriptional activators of MKP1. ${ }^{65,66} \mathrm{An}$ other study ascribed GC-stimulated MKP1 expression to a tethering mechanism involving CCAAT/enhancer-binding protein $\beta$, independent of $\mathrm{GC}$ receptor-binding. ${ }^{67}$ Conversely, a more recent study demonstrated a mechanism of MKP1 gene regulation by GCs involving GC receptor activity at a novel GC-responsive region. ${ }^{68} \mathrm{Wu}$ and colleagues ${ }^{69}$ have described both intronic and exonic regulation of MKP1 by p53. A prior report from our laboratory demonstrated a role for MIF as a potent regulator of p53 expression in RA, as evidenced by MIFmediated inhibition of p53 expression in RA FLS and modulation of p53-mediated events including apoptosis and proliferation. ${ }^{7}$ Given that MKP1 is a transcriptional target of p53, we evaluated p53 involvement in MIF regulation of MKP1, and our results indicate that p53 is not the signaling intermediate involved in MIF regulation of GC-induced MKP1 expression (data not shown). Further efforts to elucidate this signaling intermediate led us to identify a previously unrecognized intronic NBRE on the human MKP1 gene. NURR1-mediated gene transactivation has mostly been described for positively regulated genes ${ }^{39,51,52}$ and reports of repression by NURR1 are only beginning to emerge. ${ }^{38}$ EMSA experiments demonstrated rMIF-enhanced binding to the NBRE identified on the MKP1 gene, and MKP1-luc reporter experiments confirmed the contribution of the NBRE to NURR1-mediated repression of GC-induced MKP1. The involvement of NURR1 in the transcriptional regulation of $M K P 1$ is consistent with the patterns of temporal regulation of both NURR1 and MKP1 in RA FLS, as both are immediate early genes. Collectively, our results are consistent with a role for MIF as an enhancer of the expression and activity of NURR1, which in turn can function as a regulator of MKP1 expression through the NBRE, a repressive site on the MKP1 gene. Thus, we propose a role for NURR1 as a previously unrecognized mediator of GC and MIF effects on MKP1.

An interesting implication of a mechanistic link between NURR1 and MKP1 may extend to the molecular mechanisms underlying steroid-induced osteoporosis, a serious side-effect of GCs. NURR1 regulates the expression of osteopontin and osteocalcin, important bone matrix proteins involved in osteoblast maturation. ${ }^{51,52}$ Both in vitro and in vivo studies have demonstrated NURR1 induction by the bone-resorptive hormone PTH in osteoblasts and PTH target tissues, ${ }^{53,70}$ and more recent studies ascribe a role to NURR1 as a mediator of PTHinduced changes in bone metabolism. ${ }^{71,72} \mathrm{PTH}$ has been shown to modulate MAPK signaling in osteoblasts through induction of MKP1 ${ }^{19}$ and, importantly, MKP1 has been identified as a mediator of GC-induced inhibition of osteoblast proliferation. ${ }^{31} \mathrm{~A}$ recent study demonstrated the critical role of MKP1 in the maintenance of bone mass through negative regulation of MAPK-dependent osteoclast signaling. ${ }^{73}$ Thus, it is tempting to speculate that concerted signaling between NURR1 and MKP1, both GC- and MIF-responsive inflammatory mediators, may be involved in steroid-induced osteoporosis.

Inflammatory diseases represent a challenge for therapeutic intervention due to the complex inflammatory signaling pathways underlying their pathogenesis and the dose-dependent complications arising from therapeutic GCs. MKP1 is now recognized as a critical regulator of MAPK-dependent inflammatory and immune responses, and GCs harness MKP1 to exert their anti-inflammatory effects. The ability of MIF to counteract the stimulatory effects of GCs on MKP1 expression has been associated with its effects on GC sensitivity. The present study describes an underlying molecular mechanism of MKP1 regulation via 
the nuclear orphan receptor NURR1. The identification of NURR1 as a target of both GCs and MIF in mediating their opposing effects on MKP1 positions NURR1 as a participant in a critical regulatory network that influences innate and adaptive immune responses, and disease phenotypes. Moreover, the addition of MKP1 to the repertoire of NURR1regulated genes gives credence to the notion of targeting this orphan receptor therapeutically.

\section{Acknowledgments}

We thank William James for confocal microscopy assistance, Dr. Zhonglin Chai for assistance with the p53 study, and Associate Professor Michael Hickey for statistics advice. We thank Dr. Alice McEvoy for assistance with generating the NURR1 ectopically expressing cell lines and Dr. Kimberlee Mix for helpful discussions.

\section{References}

1. Tak PP, Bresnihan B: The pathogenesis and prevention of joint damage in rheumatoid arthritis: advances from synovial biopsy and tissue analysis. Arthritis Rheum 2000, 43:2619-2633

2. Ben-Av P, Crofford LJ, Wilder RL, Hla T: Induction of vascular endothelial growth factor expression in synovial fibroblasts by prostaglandin $\mathrm{E}$ and interleukin-1: a potential mechanism for inflammatory angiogenesis. FEBS Lett 1995, 372:83-87

3. Leech M, Metz C, Hall P, Hutchinson P, Gianis K, Smith M, Weedon H, Holdsworth SR, Bucala R, Morand EF: Macrophage migration inhibitory factor in rheumatoid arthritis: evidence of proinflammatory function and regulation by glucocorticoids. Arthritis Rheum 1999, 42:1601-1608

4. Schett G, Tohidast-Akrad M, Smolen JS, Schmid BJ, Steiner CW, Bitzan P, Zenz P, Redlich K, Xu Q, Steiner G: Activation, differential localization, and regulation of the stress-activated protein kinases, extracellular signal-regulated kinase, c-JUN N-terminal kinase, and p38 mitogen-activated protein kinase, in synovial tissue and cells in rheumatoid arthritis. Arthritis Rheum 2000, 43:2501-2512

5. Chrousos GP: The hypothalamic-pituitary-adrenal axis and immunemediated inflammation. N Engl J Med 1995, 332:1351-1362

6. Leech M, Metz C, Bucala R, Morand EF: Regulation of macrophage migration inhibitory factor by endogenous glucocorticoids in rat adjuvant-induced arthritis. Arthritis Rheum 2000, 43:827-833

7. Leech M, Lacey D, Xue JR, Santos L, Hutchinson P, Wolvetang E, David JR, Bucala R, Morand EF: Regulation of p53 by macrophage migration inhibitory factor in inflammatory arthritis. Arthritis Rheum 2003, 48:1881-1889

8. Leech M, Metz C, Santos L, Peng T, Holdsworth SR, Bucala R, Morand EF: Involvement of macrophage migration inhibitory factor in the evolution of rat adjuvant arthritis. Arthritis Rheum 1998, 41:910-917

9. Santos LL, Lacey D, Yang Y, Leech M, Morand EF: Activation of synovial cell p38 MAP kinase by macrophage migration inhibitory factor. J Rheumatol 2004, 31:1038-1043

10. Santos LL, Dacumos A, Yamana J, Sharma L, Morand EF: Reduced arthritis in MIF deficient mice is associated with reduced $\mathrm{T}$ cell activation: down-regulation of ERK MAP kinase phosphorylation. Clin Exp Immunol 2008, 152:372-380

11. Sampey AV, Hall PH, Mitchell RA, Metz CN, Morand EF: Regulation of synoviocyte phospholipase A2 and cyclooxygenase 2 by macrophage migration inhibitory factor. Arthritis Rheum 2001, 44:12731280

12. Onodera S, Ohshima S, Tohyama H, Yasuda K, Nishihira J, Iwakura Y, Matsuda I, Minami A, Koyama Y: A novel DNA vaccine targeting macrophage migration inhibitory factor protects joints from inflammation and destruction in murine models of arthritis. Arthritis Rheum 2007, 56:521-530

13. Pakozdi A, Amin MA, Haas CS, Martinez RJ, Haines GK, 3rd, Santos
LL, Morand EF, David JR, Koch AE: Macrophage migration inhibitory factor: a mediator of matrix metalloproteinase-2 production in rheumatoid arthritis. Arthritis Res Ther 2006, 8:R132

14. Piette C, Deprez M, Roger T, Noel A, Foidart JM, Munaut C: The dexamethasone-induced inhibition of proliferation, migration and invasion in glioma cell lines is antagonized by macrophage migration inhibitory factor (MIF) and can be enhanced by specific MIF inhibitors. J Biol Chem 2009, 284:32483-32492

15. Aeberli D, Yang Y, Mansell A, Santos L, Leech M, Morand EF: Endogenous macrophage migration inhibitory factor modulates glucocorticoid sensitivity in macrophages via effects on MAP kinase phosphatase-1 and p38 MAP kinase. FEBS Lett 2006, 580:974-981

16. Roger T, Chanson AL, Knaup-Reymond M, Calandra T: Macrophage migration inhibitory factor promotes innate immune responses by suppressing glucocorticoid-induced expression of mitogen-activated protein kinase phosphatase-1. Eur J Immunol 2005, 35:3405-3413

17. Liu Y, Shepherd EG, Nelin LD: MAPK phosphatases-regulating the immune response. Nat Rev Immunol 2007, 7:202-212

18. Franklin CC, Kraft AS: Conditional expression of the mitogen-activated protein kinase (MAPK) phosphatase MKP-1 preferentially inhibits p38 MAPK and stress-activated protein kinase in U937 cells. J Biol Chem 1997, 272:16917-16923

19. Lai LP, Mitchell J: Parathyroid hormone inhibits phosphorylation of mitogen-activated protein kinase (MAPK) ERK1/2 through inhibition of c-Raf and activation of MKP-1 in osteoblastic cells. Cell Biochem Funct 2009, 27:269-275

20. Lasa M, Abraham SM, Boucheron C, Saklatvala J, Clark AR: Dexamethasone causes sustained expression of mitogen-activated protein kinase (MAPK) phosphatase 1 and phosphatase-mediated inhibition of MAPK p38. Mol Cell Biol 2002, 22:7802-7811

21. Brondello JM, Brunet A, Pouyssegur J, McKenzie FR: The dual specificity mitogen-activated protein kinase phosphatase- 1 and -2 are induced by the p42/p44MAPK cascade. J Biol Chem 1997, 272 : 1368-1376

22. Toh ML, Yang $Y$, Leech M, Santos L, Morand EF: Expression of mitogen-activated protein kinase phosphatase 1, a negative regulator of the mitogen-activated protein kinases, in rheumatoid arthritis: upregulation by interleukin-1beta and glucocorticoids. Arthritis Rheum 2004, 50:3118-3128

23. Sanchez-Tillo E, Comalada M, Xaus J, Farrera C, Valledor AF, Caelles C, Lloberas J, Celada A: JNK1 is required for the induction of Mkp1 expression in macrophages during proliferation and lipopolysaccharide-dependent activation. J Biol Chem 2007, 282:12566-12573

24. Chi H, Barry SP, Roth RJ, Wu JJ, Jones EA, Bennett AM, Flavell RA Dynamic regulation of pro- and anti-inflammatory cytokines by MAPK phosphatase 1 (MKP-1) in innate immune responses. Proc Natl Acad Sci USA 2006, 103:2274-2279

25. Maier JV, Brema S, Tuckermann J, Herzer U, Klein M, Stassen M, Moorthy A, Cato AC: Dual specificity phosphatase 1 knockout mice show enhanced susceptibility to anaphylaxis but are sensitive to glucocorticoids. Mol Endocrinol 2007, 21:2663-2671

26. Salojin KV, Owusu IB, Millerchip KA, Potter M, Platt KA, Oravecz T: Essential role of MAPK phosphatase-1 in the negative control of innate immune responses. J Immunol 2006, 176:1899-1907

27. Wu JJ, Roth RJ, Anderson EJ, Hong EG, Lee MK, Choi CS, Neufer PD Shulman GI, Kim JK, Bennett AM: Mice lacking MAP kinase phosphatase-1 have enhanced MAP kinase activity and resistance to diet-induced obesity. Cell Metab 2006, 4:61-73

28. Wang X, Zhao Q, Matta R, Meng X, Liu X, Liu CG, Nelin LD, Liu Y Inducible nitric oxide synthase expression is regulated by MAP kinase phosphatase-1. J Biol Chem 2009, 284:27123-27134

29. Zhao Q, Wang X, Nelin LD, Yao Y, Matta R, Manson ME, Baliga RS, Meng X, Smith CV, Bauer JA, Chang CH, Liu Y: MAP kinase phosphatase 1 controls innate immune responses and suppresses endotoxic shock. J Exp Med 2006, 203:131-140

30. Zhao Q, Shepherd EG, Manson ME, Nelin LD, Sorokin A, Liu Y: The role of mitogen-activated protein kinase phosphatase-1 in the response of alveolar macrophages to lipopolysaccharide: attenuation of proinflammatory cytokine biosynthesis via feedback control of p38. J Biol Chem 2005, 280:8101-8108

31. Horsch $K$, de Wet $H$, Schuurmans MM, Allie-Reid F, Cato AC, Cunningham J, Burrin JM, Hough FS, Hulley PA: Mkp-1/Dusp1 mediates glucocorticoid inhibition of osteoblast proliferation. Mol Endocrinol 2007, 21:2929-2940 
32. Abraham SM, Lawrence T, Kleiman A, Warden P, Medghalchi M, Tuckermann J, Saklatvala J, Clark AR: Anti-inflammatory effects of dexamethasone are partly dependent on induction of dual specificity phosphatase 1. J Exp Med 2006, 203:1883-1889

33. Kassel O, Sancono A, Kratzschmar J, Kreft B, Stassen M, Cato AC: Glucocorticoids inhibit MAP kinase via increased expression and decreased degradation of MKP-1. EMBO J 2001, 20:7108-7116

34. Murphy EP, Conneely OM: Neuroendocrine regulation of the hypothalamic pituitary adrenal axis by the nurr $1 /$ nur 77 subfamily of nuclear receptors. Mol Endocrinol 1997, 11:39-47

35. Zetterstrom RH, Solomin L, Jansson L, Hoffer BJ, Olson L, Perlmann T: Dopamine neuron agenesis in Nurr1-deficient mice. Science 1997, 276:248-250

36. Saijo K, Winner B, Carson CT, Collier JG, Boyer L, Rosenfeld MG, Gage FH, Glass CK: A Nurr1/CoREST pathway in microglia and astrocytes protects dopaminergic neurons from inflammation-induced death. Cell 2009, 137:47-59

37. Chu Y, Le W, Kompoliti K, Jankovic J, Mufson EJ, Kordower JH: Nurr1 in Parkinson's disease and related disorders. J Comp Neurol 2006 494:495-514

38. Mix KS, Attur MG, Al-Mussawir H, Abramson SB, Brinckerhoff CE, Murphy EP: Transcriptional repression of matrix metalloproteinase gene expression by the orphan nuclear receptor NURR1 in cartilage. J Biol Chem 2007, 282:9492-9504

39. Murphy EP, McEvoy A, Conneely OM, Bresnihan B, FitzGerald O: Involvement of the nuclear orphan receptor NURR1 in the regulation of corticotropin-releasing hormone expression and actions in human inflammatory arthritis. Arthritis Rheum 2001, 44:782-793

40. Arkenbout EK, de Waard V, van Bragt M, van Achterberg TA, Grimbergen JM, Pichon B, Pannekoek H, de Vries CJ: Protective function of transcription factor TR3 orphan receptor in atherogenesis: decreased lesion formation in carotid artery ligation model in TR3 transgenic mice. Circulation 2002, 106:1530-1535

41. Aherne CM, McMorrow J, Kane D, Fitzgerald O, Mix KS, Murphy EP: Identification of NR4A2 as a transcriptional activator of IL-8 expression in human inflammatory arthritis. Mol Immunol 2009, 46 3345-3357

42. Holla VR, Mann JR, Shi Q, DuBois RN: Prostaglandin E2 regulates the nuclear receptor NR4A2 in colorectal cancer. J Biol Chem 2006 281:2676-2682

43. Pei L, Castrillo A, Chen M, Hoffmann A, Tontonoz P: Induction of NR4A orphan nuclear receptor expression in macrophages in response to inflammatory stimuli. J Biol Chem 2005, 280:29256-29262

44. Ralph JA, McEvoy AN, Kane D, Bresnihan B, FitzGerald O, Murphy EP: Modulation of orphan nuclear receptor NURR1 expression by methotrexate in human inflammatory joint disease involves adenosine A2A receptor-mediated responses. J Immunol 2005, 175:555-565

45. Bonta PI, van Tiel CM, Vos M, Pols TW, van Thienen JV, Ferreira V, Arkenbout EK, Seppen J, Spek CA, van der Poll T, Pannekoek H, de Vries CJ: Nuclear receptors Nur77, Nurr1, and NOR-1 expressed in atherosclerotic lesion macrophages reduce lipid loading and inflammatory responses. Arterioscler Thromb Vasc Biol 2006, 26:2288-2294

46. McEvoy AN, Murphy EA, Ponnio T, Conneely OM, Bresnihan B, FitzGerald O, Murphy EP: Activation of nuclear orphan receptor NURR1 transcription by NF-kappa B and cyclic adenosine 5'-monophosphate response element-binding protein in rheumatoid arthritis synovial tissue. J Immunol 2002, 168:2979-2987

47. Maxwell MA, Muscat GE: The NR4A subgroup: immediate early response genes with pleiotropic physiological roles. Nucl Recept Signal 2006, 4:e002

48. Nordzell M, Aarnisalo P, Benoit G, Castro DS, Perlmann T: Defining an $\mathrm{N}$-terminal activation domain of the orphan nuclear receptor Nurr 1. Biochem Biophys Res Commun 2004, 313:205-211

49. Galleguillos D, Vecchiola A, Fuentealba JA, Ojeda V, Alvarez K, Gomez A, Andres ME: PIASgamma represses the transcriptional activation induced by the nuclear receptor Nurr1. J Biol Chem 2004, 279:2005-2011

50. Carpentier R, Sacchetti P, Segard P, Staels B, Lefebvre P: The glucocorticoid receptor is a co-regulator of the orphan nuclear receptor Nurr1. J Neurochem 2008, 104:777-789

51. Lammi J, Huppunen J, Aarnisalo P: Regulation of the osteopontin gene by the orphan nuclear receptor NURR1 in osteoblasts. Mol Endocrinol 2004, 18:1546-1557

52. Pirih FQ, Tang A, Ozkurt IC, Nervina JM, Tetradis S: Nuclear orphan receptor Nurr1 directly transactivates the osteocalcin gene in osteoblasts. J Biol Chem 2004, 279:53167-53174

53. Tetradis S, Bezouglaia O, Tsingotjidou A: Parathyroid hormone induces expression of the nuclear orphan receptor Nurr1 in bone cells. Endocrinology 2001, 142:663-670

54. Engelbrecht $\mathrm{Y}$, de Wet $\mathrm{H}$, Horsch $\mathrm{K}$, Langeveldt $\mathrm{CR}$, Hough FS, Hulley PA: Glucocorticoids induce rapid up-regulation of mitogenactivated protein kinase phosphatase- 1 and dephosphorylation of extracellular signal-regulated kinase and impair proliferation in human and mouse osteoblast cell lines. Endocrinology 2003, 144:412-422

55. Wu Y, Ghosh S, Nishi Y, Yanase T, Nawata H, Hu Y: The orphan nuclear receptors NURR1 and NGFI-B modulate aromatase gene expression in ovarian granulosa cells: a possible mechanism for repression of aromatase expression upon luteinizing hormone surge. Endocrinology 2005, 146:237-246

56. McEvoy AN, Bresnihan B, FitzGerald O, Murphy EP: Cyclooxygenase 2-derived prostaglandin E2 production by corticotropin-releasing hormone contributes to the activated CAMP response element binding protein content in rheumatoid arthritis synovial tissue. Arthritis Rheum 2004, 50:1132-1145

57. Krause A, Holtmann H, Eickemeier S, Winzen R, Szamel M, Resch K, Saklatvala J, Kracht M: Stress-activated protein kinase/Jun N-terminal kinase is required for interleukin (IL)-1-induced IL-6 and IL-8 gene expression in the human epidermal carcinoma cell line KB. J Biol Chem 1998, 273:23681-23689

58. Jackson JR, Bolognese B, Hillegass L, Kassis S, Adams J, Griswold DE, Winkler JD: Pharmacological effects of SB 220025, a selective inhibitor of P38 mitogen-activated protein kinase, in angiogenesis and chronic inflammatory disease models. J Pharmacol Exp Ther 1998, 284:687-692

59. Han Z, Chang L, Yamanishi Y, Karin M, Firestein GS: Joint damage and inflammation in C-Jun $\mathrm{N}$-terminal kinase 2 knockout mice with passive murine collagen-induced arthritis. Arthritis Rheum 2002, 46:818-823

60. Mengshol JA, Vincenti MP, Coon Cl, Barchowsky A, Brinckerhoff CE: Interleukin-1 induction of collagenase 3 (matrix metalloproteinase 13) gene expression in chondrocytes requires p38, c-Jun $\mathrm{N}$-terminal kinase, and nuclear factor kappaB: differential regulation of collagenase 1 and collagenase 3 . Arthritis Rheum 2000, 43:801-811

61. Pei L, Castrillo A, Tontonoz P: Regulation of macrophage inflammatory gene expression by the orphan nuclear receptor Nur77. Mol Endocrinol 2006, 20:786-794

62. Martinez-Gonzalez J, Rius J, Castello A, Cases-Langhoff C, Badimon $\mathrm{L}:$ Neuron-derived orphan receptor-1 (NOR-1) modulates vascular smooth muscle cell proliferation. Circ Res 2003, 92:96-103

63. Onodera S, Nishihira J, Koyama Y, Majima T, Aoki Y, Ichiyama H, Ishibashi T, Minami A: Macrophage migration inhibitory factor upregulates the expression of interleukin-8 messenger RNA in synovial fibroblasts of rheumatoid arthritis patients: common transcriptional regulatory mechanism between interleukin-8 and interleukin-1beta. Arthritis Rheum 2004, 50:1437-1447

64. Doi M, Cho S, Yujnovsky I, Hirayama J, Cermakian N, Cato AC, Sassone-Corsi P: Light-inducible and clock-controlled expression of MAP kinase phosphatase 1 in mouse central pacemaker neurons. J Biol Rhythms 2007, 22:127-139

65. Furst R, Zahler S, Vollmar AM: Dexamethasone-induced expression of endothelial mitogen-activated protein kinase phosphatase-1 involves activation of the transcription factors activator protein-1 and $3^{\prime}, 5^{\prime}$-cyclic adenosine $5^{\prime}$-monophosphate response element-binding protein and the generation of reactive oxygen species. Endocrinology 2008, 149:3635-3642

66. Casals-Casas C, Alvarez E, Serra M, de la Torre C, Farrera C, Sanchez-Tillo E, Caelles C, Lloberas J, Celada A: CREB and AP-1 activation regulates MKP-1 induction by LPS or M-CSF and their kinetics correlate with macrophage activation versus proliferation. Eur J Immunol 2009, 39:1902-1913

67. Johansson-Haque K, Palanichamy E, Okret S: Stimulation of MAPK phosphatase 1 gene expression by glucocorticoids occurs through a tethering mechanism involving C/EBP. J Mol Endocrinol 2008, 41:239-249

68. Tchen CR, Martins JR, Paktiawal N, Perelli R, Saklatvala J, Clark AR: Glucocorticoid regulation of mouse and human dual specificity phos- 
phatase 1 (DUSP1) genes: unusual cis-acting elements and unexpected evolutionary divergence. J Biol Chem 2009, 285:2642-2652

69. Yang H, Wu GS: p53 Transactivates the phosphatase MKP1 through both intronic and exonic p53 responsive elements. Cancer Biol Ther 2004, 3:1277-1282

70. Pirih FQ, Aghaloo TL, Bezouglaia O, Nervina JM, Tetradis S: Parathyroid hormone induces the NR4A family of nuclear orphan receptors in vivo. Biochem Biophys Res Commun 2005, 332:494-503

71. Zierold C, Nehring JA, DeLuca HF: Nuclear receptor 4 A2 and C/EBPbeta regulate the parathyroid hormone-mediated transcriptional regulation of the 25-hydroxyvitamin D3-1alpha-hydroxylase. Arch Biochem Biophys 2007, 460:233-239

72. Nervina JM, Magyar CE, Pirih FQ, Tetradis S: PGC-1alpha is induced by parathyroid hormone and coactivates Nurr1-mediated promoter activity in osteoblasts. Bone 2006, 39:1018-1025

73. Carlson J, Cui W, Zhang Q, Xu X, Mercan F, Bennett AM, Vignery A Role of MKP-1 in osteoclasts and bone homeostasis. Am J Pathol 2009, 175:1564-1573 